he was reported well, and had suffered no return of febrile symptoms.

Remarks.-This is an unusual, and in some respects a remarkable, case. Although I have met with several instances of unaccountable pyrexia in adults, and especially in children, I have no record or remembrance of any case resembling in its features the one under consideration. Were the symptoms due to some alteration or disturbance in the nervous centres originating in the fall on the head? Were they dependent upon suppuration in the middle ear, or on some undetected condition of disturbance of the digestive system? There is much to recommend the first view. The boy was of a nervous and excitable temperament, and his condition on several occasions closely approached that of "hysteria" in the opposite sex. Moreover, the extraordinary variations in the temperature were suggestive of a neurotic origin. So, too, there were none of the constitutional signs of fever that would have necessarily accompanied a pyrexia of this kind if dependent on the usual causes. The drowsy and lethargic state has often been noted in neurotic individuals, in some cases leading to trance, or the uine days' wonder of a sleeping girl. Yet we have to recollect, on the other hand, that deeply seated collections of matter are often only signified by curious variations in temperature, and that excessive drowsiness with fever is often symptomatic of ear mischief. The rapid improvement of the boy after the discharge of pus would lend some colour to this view of the case. For the first few days I was inclined to think that pulmonary tubercle might be the slumbering element of mischief in this case, as evidenced by the protracted bronchial irritation. But when this had passed off, and there were no special signs of tuberculosis, it appeared to me improbable. The true import of such a high temperature was indeed doubtful. And in this, as in all such cases, I thought it wise to exercise vigilant supervision, and enjoin the strictest rest of mind and body. A remarkable feature in the case was the tendency to drowsiness and torpor. This was an early and constant symptom, and pointed to some important change in the nervous centres. Throughout the illness there was great lethargy, and during much of the time profound stupor, from which he could not be always roused. He generally lay on his left side, with calm features, and when asleep he had quiet respiration and slow pulse. It seemed whilst this drowsy state continued that he might pass into a comatose condition and die. Such a termination seemed not improbable if the potient was not roused to take nourishment. Pyrexia occurring without the general symptoms of fever is especially likely to occur from slight causes in neurotic individuals. It is quite likely that the true explanation of this case hinges on this observation. A delicate and sensitive lad gets the sequence of events not uncommonly noticed. A blow on the head, some suppuration about the tympanic cavity, possibly old mischief lighted up into fresh activity, and a curious train of febrile and head symptoms supervene. In an older person, or a lad of more stolid temperament, the symptoms would probably have been less complicated; but the case affords a striking instance of the readiness with which the temperature of a boy may undergo curious variations, and the great difficulty we often have in practice to trace such complications to their true origin.

\section{ANTIPYRIN AS AN ANODYNE.}

\section{Bx OSCAR JENNINGS, M.D.}

THE remarkable effect of antipyrin in the treatment of pain attracting general attention at present, the following cases may be of interest to the readers of THE LANCET.

1. A middle-aged lady with slight ataxic symptoms, including loss of knee jerk, whose chief trouble consisted of intermitting darting pains in the thighs and legs, and constant burning pains in the heels. She was supposed by consultants to have an arthritic affection of the sheath of the cord. Iodide, quinine, colchicum, salicylates, and electricity in various forms, had been all used without success Antipyrin proved entirely useless, but the patient was slightly improved by a season at Lamalou.

2. A stout middle-aged female medical attendant, a large eater, and unable to get any exercise except in a carriage with her employer, was suffering from subacute gout in the foot. She took four grammes of antipyrin daily for a week and probably independent of the medicine.

3. A stout man, thirty years of age, head waiter in a Paris restaurant, suffering from acute gout, was relieved by the same doses in twenty-four hours.

4. An unmarried middle-aged Iady, crippled by double sciatica, which obliges her to use two sticks to get about and who suffers more or less constantly from pain, had tried everything that could be suggested. She tried antipyrin, and it was unsuccessful.

5. A gentleman, aged sixty-nine, was sent to me for a painful affection about the shoulder, which had resisted all kinds of treatment directed by the most eminent neurologists in America. The malady had been variously described as neuralgia, neuritis, and myositis. The symptoms consisted of periodical paroxysms of pain, recurring at night, with inability to move the arms upwards and backwards (to brush the hair, for instance) without causing painful spasm in the muscle. There was also a dull, fixed pain in the right side, and hypochondriasis. Professor Ball who had recommended the patient to place himself under my care for an electrical treatment, prescribed iodide of potassium and euonymin, by which the pain in the side was permanently relieved. The improvement about the shoulder joint, however, was slow, and the patient, who had expected to be entirely cured by electricity in a month, was becoming discouraged. Profersor Sée's communication appearing at this juncture, it was decided to give antipyrin a trial. At first it had but little effect, but after a fow days' administration by the mouth hypodermic injections were used instead, with a satisfactory result. The patient, if not cured, recognised that he was greatly improved in every respect - a statement endorsed more strongly by all his friends.

6. A washerwoman, aged forty-nine, was attending at the clinique of St. Anne with precisely the same symptoms, and, besides limitation of the movements upwards and backwards by pain, there was considerable wasting of the muscles. Faradic electricity had been employed for six weeks with the best effect; the paroxysms of pain were relieved, movement improved, and the volume of the muscles restored. The patient, although at considerable inconvenience to herself, never failed to attend the electrical room for treatment. There remained, however, a dull pain to which she was so accustomed that it was no longer subject of complaint, and was only mentioned when she was interrogated upon this point. Encouraged by my experience in the preceding case, I again tried antipyrin hypodermically, with an excellent result. The patient now takes one gramme per day and is free from pain, any movement being possible without uneasiness.

7. Antipyrin being said to relieve pain by lessening the perceptibility of the nervous centres, I thought it might be worth a trial in the morphia craving. I gave it in one case which has been already mentioned in the columns of THE LANCET, but the result was not encouraging. The patient stated that it made the craving worse. This, how. ever, may have been a wilful representation for the sake of obtaining a little more morphia. He said, moreover, that he felt sick and giddy, and, as a matter of fact, he did not look well.

8. Upon the same theoretical grounds 1 gave antipyrin in one case of sea-sickness with good effect.

9. The most striking benefit $I$ have seen following the use of this drug was in the following case :-An American gentleman, an artist, had been overtaxing both body and brain for some time in order to get a picture finished. He had been working in a cold atelier, taking meals irregularly, and was morbidly anxious as to success. He bad already lost appetite and become sleepless and restless, when he wos seized with violent abdominal pains, accompanied by frequent stools containing blood, cerebral excitement, and subdelirium, with fear of impending death or insanity. He was the more excited when I saw him ingsmuch ss he had been anxiously waiting for an English doctor the whole afternoon, and was just then threatened with 8 visitation from no less than three. A collesgue who arrived shortly after myself suggested the possibility of ryphoid, but, as the management of the case devolved upon me, 1 accepted the diagnosis of the family, which was riscersl rheumatism, ordered a morphiz suppository and a mixture containing chloral and bromide to allay the symptoms dependivg upon the brain. The next day the pain was stil severe, although the mental excitement was lessened, and 
the patient begged for a hypodermic injection of morphia, which, he said had been used with benefit upon a previous occasion. This I gave, and was called upon to repeat the dose in the evening. The next morning morphia was again demanded and given, and as $I$ had resolved not to make any more hypodermic injections, I told the patient I could give him no more morphia except in the form of suppositories, and prescribed antipyrin, to be taken in fifteen-grain doses every four hours. The administration was commenced under the influence of the last hypodermic injection, and the pain never returned, the patient rapidly convalescing and leaving Paris shortly after for the United States.

10. I have given antipyrin in one case of zona. The pain disappeared after the third dose of fifteen grains "like a charm," to use the patient's own expression.

11. Of two cases of inflamed painful sore-throat of rheumatic origin, one was greatly relieved.

12. In migraine there can be no doubt as to the efficacy of antipyrin for a time, although, in my opinion, the dose requires to be larger than those mentioned by some correspondents of THE LANCET-fifteen grains at least. I am afraid, however, that the effect will of ten be found to wear off after a time, or that it will be necessary to increase the dose to an imprudent extent. I know a lady who has been taking antipyrin for migraine for two months, and who already finds that it has lost most of its "magic" although it stil procures some relief. M. Norström tells me he has had similar experience.

To sum up. If antipyrin is not an unfailing specific, 1 have certainly seen it allay pain as speedily and more radically than a hypodermic injection of morphia. Whether any evil results are likely to follow its prolonged use remains, of course, to be seen. There is a good deal of talk at present about the possibility of benzine poisoning resulting from the admixture of this substance with the drug, owing to imperfect preparation, but I must confess that every solution I have used hypodermically has smelt of benzine, and until the end of September, when I purchased an inodorous sample in London, I was under the impression that this was al ways the case. Like others I have frequently seen giddiness, vertigo, and nausea follow the administration of antipyrin, and ecchymoses and induration at the seat of injection. In one instance where I had associated it with cocaine, according to a formula much used in Paris, the patient felt prostrate and missrable for four or five days. This has never occurred with antipyrin alone. Paris.

\section{ANTIPYRIN IN THE TREATMENT OF MIGRAINE.}

Bx W. H. RUSSELL FORSBROOK, M.B.LOND.

So far as I know, the treatment of this troublesome and frequent disease by antipyrin has not been tried in this country. I was induced to try it in the first instance after having read an account of the drug in THE LANCET, written by a German physician, who had given it with success in this and various neuralgias; and I have now myself prescribed it in some hundred cases with an almost magical result. The causes and symptoms of migraine are well known, but its pathology is not so clear, and its treatment by the numerous remedies hitherto recommended has effected little or nothing, in the majority of cases, in shortening an attack. I think, therefore, the misery, depression, and extreme feeling of illness it causes while it lasts, and the almost immediate relief from all this, are a sufficient excuse for venturing to write a short account of my experience of its treatment by this drug.

I have found antipyrin given in fifteen-grain doses every twenty minutes three times consecutively almost invariably removes the pain, depression, drowsiness, nausea, \&c., so that in forty miuutes, frequently even after one dose, patients express themselves quite well. A singledose, if given during the premonitory signs, will often ward off an attack Sometimes I recommend another dose in four hours, but, not of ten, as I find the very few cases in which there has not been absolute removal of pain after the third dose, but only partial relief, are seldom further affected. These $\mathrm{f} \theta \mathrm{w}$ cases, however, which are not amenable to the speedy action of the medicine, seem to have the duration of the attack much shortened. One important fact is noticeable, that the period between the attacks has seemed to me to be prolonged; also that succeeding attacks have not been so severe after its administration The pulse, which is generally slowed during an attack of migraine, appears in some cases to be rendered fuller and quicker. Antipyrin, when given to young women for migraine, sometimes produces a species of intoxication, so that it is as well to be on one's guard; although, so far as my limited experience goes, the only result has been the almost certain and immediate relief from the peculiar pain \&c.

According to one theory of its pathology-that of Dr. Liveing,-migraine has a close pathological relation to epilepsy ; although one disease is said never to pass into the other. Dr. Liveing thinks that the immediate antecedent of the attack is a state of unstable equilibrium and gradually accumulating tension in the parts of the nervous system especially involved, the paroxysm being somewhat similar to a storm. He considers the seat of the disease to be the optic thalami and the parts between those bodies and the roots of the vagi. Thinking of this close relationship between the two diseases, I commenced to give antipyrin in the headache following an epileptic seizure, and I was glad to find that it acted quite as well as in ordinary migraine in six out of seven cases. I have also prescribed it, following out the analogy, in those cases of epilepsy indicated by premonitory symptoms, or by the so-called aura epileptica, and in the only two cases in which I have tried it I certainly believe that it preventea an attack in one of them; but naturally the drug requires a much more lengthy and searching trial with respect to the headache following an attack of epilepsy, and especially as to its power in the prevention of an attack preceded by an aura, and I merely throw out these hints in the hope that someone with extensive practice in epilepsy will experiment. I have most certainly proved the great value of antipyrin in migraine in my own practice, and I ask others to prescribe it in order to be convinced of its specific action.

Buckingham-palace-road, s.W.

\section{MERCURIC BINLODIDE GAUZE :} A NEW ANTISEPTIC DRESSING.

BY J. C. V O I GT, M.D. EDIN.,

LATE SENIOR RESIDENT MEDICAL OFFICER, BURY INFIRMARY.

Since Jan. 1st, 1886, I have used a gauze prepared in the following way. Plain absorbent gauze is steeped in a 1 in 500 solution of mercuric biniodide in iodide of potassium and glycerine: Hydrarg. iod. rubr, $1 \mathrm{dr}$.; pot. iod., $3 \mathrm{dr}$.; glycerine, $4 \mathrm{oz}$; aqua ad $80 \mathrm{oz}$. After being well soaked in this solution, the gauze is squeezed out and hung to dry in a darkened room. For irrigation of wounds and washing out of abscess cavities I employ a stock solution of hydrarg. iod. rubr., 2 dr.; pot. iod. 4 dr.; glycerine, $12 \mathrm{oz}$; a qua ad $80 \mathrm{oz}$. This is diluted (with water) from four to eight times before being used. The solutions thus diluted are substitutes for the 1 in 1000 and 1 in 2000 corrosive sublimate solutions. For the dressing of ulcers much weaker solutions-1 in 20,000 and 1 in 40,000 - have been employed. The following cases are given as illustrations of the foregoing :-

1. Right-sided empyema-Lilias A- aged eight years. Empyema opened Jan. 15th 1886. Cavity syringed out with 1 in 10,000 biniodide solution, and drainage tubes inserted. Washed out daily with the solution (diluted to 1 in 20,000 after the third day) and tubes shortened. Drainage tubes removed in three weeks. Patient discharged cured.

2. Deep cellular inflammation and suppuration under the scalp (after a blow on the head). - Nancy $\mathrm{H}-$ - aged fortyone. Treatment commenced on Feb.3rd, 1886. High evening temperatures and rigors. Suppuration, involving nearly half the scalp. Free incision and drainage. Syringing with the 1 in 1000 biniodide solution, and dressing with biniodide gauze. Cured by Feb. 15th.

3. Thomas $R$-, aged thirty-seren. Similar case to the above (after wound of scalp). Here the biniodide solution was substituted for the corrosive sublimate on the third day of treatment, after drainage-tubes had been inserted and counter-openings made. The amount of discharge was noted as being "much less" at the following dressing. The drainage tubes were gradually shortened, and the patient was discharged cured in twelve days.

4. Large axillary and subclavicular abscess. - R. Waged forty-four. Drainage tubes inserted (after free incision) into axilla, and under pectoralis major. Abscess cavity 